\title{
Teen drivers and the risk of injury to child passengers in motor vehicle crashes
}

\author{
I G Chen, M R Elliott, D R Durbin, F K Winston
}

Injury Prevention 2005;11:12-17. doi: 10.1136/ip.2004.007617

See end of article for authors' affiliations

.....................

Correspondence to: Dr Irene G Chen, Children's Hospital of Philadelphia, 34th Street and Civic Center Boulevard, 3535 Traumalink, 10th Floor Philadelphia, PA 19104, USA; cheni@email.chop. edu

\begin{abstract}
Objectives: The first aim was to examine the relationship between driver's age (novice teens, older teens, and adults) and child passenger's restraint status, front row seating, and injury risk. The second aim was to explore whether there was an excess injury risk to child passengers in teen crashes compared to those in adult crashes by examining the contributing factors.

Methods: A cross sectional study involving telephone interviews with insured drivers in a probability sample of 12163 crashes involving 19111 children was conducted. Sequential logistic regressions were employed.

Results: Among child passengers aged 4-8, appropriate restraint was $<1 \%$ for novice teens, $4.5 \%$ for older teens, and $23.6 \%$ for adults. Front row seating for children $<13$ years was more common in the novice teen group $(26.8 \%)$ than in the other two groups. Compared with children riding with adults, those with both teen groups experienced excess injury risk. After adjusting for crash severity, there was a $43 \%$ reduction in the odds ratio (OR) for novice teens (OR 1.58, 95\% confidence interval (CI) 1.14 to 2.19) and a $24 \%$ reduction for older teens (OR $2.15,95 \% \mathrm{Cl} 1.42$ to 3.26 ). After adjusting for vehicle type, child's restraint status and front row seating, there was a further $19 \%$ reduction in the OR for novice teens (OR $1.37,95 \% \mathrm{Cl} 1.00$ to 1.88 ) and a further $13 \%$ reduction for older teens (OR 1.74, 95\% $\mathrm{Cl} 1.14$ to 2.66 ). Conclusion: These findings suggest ways in which graduated driver licensing laws may be further enhanced to better protect child passengers from the excess injury risk associated with teen crashes.
\end{abstract}

t many developed countries, particularly the United States, teen driver crashes are a serious and persistent problem.

For example, in 2002, 7738 fatal crashes and 519000 injury crashes were reported among youthful drivers. ${ }^{1}$ In 2001, the economic burden of youthful driver crashes in the United States was estimated at $\$ 42.3$ billion. $^{2}$ In an effort to address teen driver safety, graduated driver licensing programs were formally introduced in many states during the late 1990s. Currently, nearly all states and the District of Columbia have some form of graduated driver licensing law. As of June 2004, 36 jurisdictions have a full graduated driver licensing system, while 26 jurisdictions have passenger restrictions during the intermediate licensing stage. ${ }^{3}$ The passenger restrictions are intended to prevent or limit the presence of teenage passengers given the additional crash risk posed by the combination of teens driving teens. ${ }^{4-6}$ However, there are variations in the duration of the restriction, the age of passengers allowed to ride with teen drivers, and the need for an adult supervisor. Most of the 26 states with passenger restrictions have exemptions for passengers who are related to the driver or are members of the driver's household. Thus, no states specifically restrict teen drivers from transporting child passengers and little is known about the contribution of teen driving to the injury of their child passengers.

We have previously reported the high prevalence of inappropriate restraint ${ }^{7}$ and front row seating ${ }^{8}$ among young child passengers, and the raised injury risk to those who were not restrained appropriately for their age ${ }^{9}$ or sat in the front seat. ${ }^{10}$ Therefore, the first aim of this study was to examine the relationship between the driver's age and the child occupant's restraint status, front row seating, and serious injury. Furthermore, based on the established teen driver safety problem, the second aim was to examine whether there was an excess injury risk to child passengers in teen crashes compared to those in adult crashes. Since factors such as crash severity, ${ }^{11-14}$ passenger's seating position ${ }^{8}$ and restraint status, ${ }^{15}{ }^{16}$ and vehicle size $^{17}$ are likely to be associated both with the injury risk for passengers and the presence of a teenage driver, these factors were examined in terms of their influence on the excess injury risk for children in teen crashes.

\section{METHODS}

\section{Study population and data collection}

Data for this cross sectional study were collected as part of the Partners for Child Passenger Safety project between 1 December 1998 and 30 November 2002. A detailed description of the overall study methods has been published previously. ${ }^{18}$ The project consists of a large scale, child specific crash surveillance system: insurance claims from State Farm Insurance Corporation (Bloomington, Illinois) function as the source of subjects, with telephone interview and on-site crash investigations serving as the primary sources of data. Vehicles qualifying for inclusion were insured by State Farm, with a model year 1990 or newer, and involved in a crash with at least one child occupant under 16 years of age. Qualifying crashes were limited to those that occurred in 15 states and the District of Columbia. After policyholders consented to participate in the study, limited data were transferred electronically to researchers at the Children's Hospital of Philadelphia and University of Pennsylvania (CHOP/Penn).

Based on the stratum of the vehicle tow status/medical treatment received by child occupant(s), a stratified cluster sample was designed in order to select vehicles (the unit of sampling) for the conduct of a telephone survey with the driver. The probabilities of selection ranged from 0.025 for

Abbreviations: AIS, Abbreviated Injury Scale; CHOP/Penn, Children's Hospital of Philadelphia and University of Pennsylvania; $\mathrm{Cl}$, confidence interval; NHTSA, National Highway Traffic Safety Administration; OR, odds ratio 
vehicles in which no child received medical treatment to 1.0 for vehicles in which a child died or was admitted to the hospital. If a vehicle was sampled, the "cluster" of all child occupants in that vehicle was included in the survey.

Drivers of sampled vehicles were contacted by phone and screened via an abbreviated survey to verify the presence of at least one child occupant with an injury. The full interview involved a 30 minute telephone survey with the driver of the vehicle and parent(s) of the involved children. Only parents and drivers 16 years of age or older were interviewed. The study protocol was reviewed and approved by the institutional review boards of both CHOP/Penn.

The eligible study population consisted of all 430308 children riding in 288187 State Farm insured vehicles. Claim representatives correctly identified $95 \%$ of eligible vehicles, and $73 \%$ of policyholders consented to participate in this study. Of these, $18 \%$ were sampled for interview and an estimated $81 \%$ of these were successfully interviewed, for an overall response rate of 56\%. Examining the characteristics of claims for which consent for the telephone survey was denied, or contact was not achieved, reveals no differences in the age, crash location (that is, state), or driveable status of the vehicle when compared to claims on which an interview was conducted.

\section{Variable definitions}

A survey instrument was designed for the telephone interview including questions regarding injuries, seating position, restraint use, and restraint type for each child occupant. Based on the Abbreviated Injury Scale (AIS) score, ${ }^{19}$ serious injuries were defined as those deemed clinically significant: all injuries with AIS scores of 2 or greater as well as AIS 1, facial and scalp lacerations injuries. The ability of parents to accurately distinguish AIS 2 or greater injuries from those less severe has been validated for all body regions of injury. ${ }^{20}$ Three driving groups were defined by driver's age: novice teen $(\leqslant 17$ years), older teen ( 18 or 19 years), and adult $(\geqslant 20$ years). According to the recommendations for age appropriate restraint and seating position for children by the American Academy of Pediatrics ${ }^{2122}$ and National Highway Traffic Safety Administration (NHTSA), ${ }^{23}{ }^{24}$ child's age was grouped as 0-3, 4-8, 9-12, and 13-15 years. Appropriate restraint use was defined as children under age 1 year or weighing less than 20 pounds $(9 \mathrm{~kg})$ who were in a rearfacing child safety seat; aged $1-3$ and over 20 pounds who were in a forward-facing child safety seat; aged 4-8 who were restrained in some form of child restraint system (typically booster seats); and aged 9-15 years who were restrained in both lap and shoulder belts. Those restrained children who were not in the above categories were defined as inappropriately restrained. A three level crash severity (that is, any intrusion, no intrusion and non-driveable, and no intrusion and driveable) was determined both by whether or not the vehicle was towed from the crash scene as indicated in the insurance claims data, and by driver report of any intrusion into the occupant compartment of the vehicle (that is, the integrity of the vehicle structure was lost and the interior space was reduced). Information on the classification of vehicles was obtained from the vehicle identification number using VINDICATOR. ${ }^{25}$

\section{Analysis plan}

All analyses were conducted on the weighted sample with weights inversely proportional to their probability of selection to reduce the selection effects introduced by the sampling procedure ${ }^{26}$ using SAS callable SUDAAN. ${ }^{27}$ The robust $\chi^{2}$ tests of association were calculated.

Odds ratios (OR) were obtained from logistic regressions to approximate the relative risk of serious injury. ${ }^{28}$ As suggested in Robertson's causal model of motor vehicle injury, ${ }^{29}$ there are several possible paths of causation whereby specific factors are proposed to explain the causes of motor vehicle occupant injury. As briefly presented here, injury results from energy generated by speed and mass necessary for the damage of vulnerable tissue. Thus, the speed and size of the vehicle are important predictors of injury risk. Inputs to the vehicle by the driver such as reaction time, vision, intelligence, and motor function are contingent on the demands of the driving environment and are hypothesized to affect injury risk through the loss of vehicle control just before a crash. Based on this model, we proposed a simplified possible causal pathway by first presenting the unadjusted association of driver age to child injury risk (model 1 ). We then adjusted for child age due to the different distribution of child age groups among the three driver groups and the different injury risk of the child age groups (model 2). Next, we adjusted for crash severity as a proxy for the speed of the vehicle (model 3), followed by adjustment for factors related to vehicle size, restraint use, and seating position (model 4). In this sequential order, we can identify the contribution of modifiable factors to the excess risk for children riding with teen drivers through causal pathways. Results of logistic regression modeling are expressed as unadjusted and adjusted OR with corresponding 95\% confidence intervals (CI).

\section{RESULTS}

Completed interviews were obtained on 19111 children in 12163 crashes representing 243352 children in 157824 crashes. Children riding with drivers with unknown age were excluded from the analyses $(n=52)$. Overall, $2.6 \%$ of the children $(\mathrm{n}=1084)$ were driven by novice teens $(\mathrm{n}=755)$, $1.6 \%(\mathrm{n}=504)$ by older teens $(\mathrm{n}=371)$, and $95.8 \%$ $(\mathrm{n}=17471)$ by adults $(\mathrm{n}=10999)$. Table 1 displays passenger, driver, and vehicle characteristics for the three driver groups. When compared with adults, both teen groups had higher percentages of older and female child passengers; children sitting in the front; and unrestrained children. In addition, more child passengers riding with both teen groups were in older vehicles, in passenger cars, and in more severe crashes. Children traveling with both teen groups had a lower percentage of having at least one adult passenger. The highest injury risk for child passengers $(5.0 \%)$ was found in the novice teen group, sequentially followed by the older teen group $(4.3 \%)$, and then by the adult group (1.5\%).

As shown in table 1, overall, more child passengers were restrained appropriately when with teen drivers compared with those with adults. However, table 2 provides age stratified distribution of child restraint status, front row seating, and serious injury among the three driver groups. The age stratified analyses demonstrate a consistent pattern of less appropriate restraint of younger child passengers with teen drivers. For example, among child passengers aged 4-8 years old, appropriate restraint use was $<1 \%$ for novice teen drivers, $4.5 \%$ for older teen drivers, and $23.6 \%$ for adult drivers $\left(\chi^{2}\right.$ test: $\left.p<0.001\right)$. Similarly, front row seating for children under age 13 riding with novice teen drivers was more common than for children with the other two driver groups, although the difference was not statistically significant (novice teen: $26.8 \%$; older teen: $14.8 \%$; adult: $14.6 \%$; $\chi^{2}$ test: $\left.p=0.31\right)$. Within each driver group, as the age of child passenger increased, the injury risk also increased. Traveling with novice teen drivers, children age $13-15$ years had the highest injury risk $(5.9 \%)$.

In table 3, model 1 presents the crude OR for child passenger injury for each teen driver group compared to adult drivers. In model 2, after adjusting for child age groups, those 


\begin{tabular}{|c|c|c|c|c|}
\hline & $\begin{array}{l}\text { Novice teen } \\
\text { ( } n=1084 \text { child } \\
\text { passengers) }\end{array}$ & $\begin{array}{l}\text { Older teen ( } n=504 \\
\text { child passengers) }\end{array}$ & $\begin{array}{l}\text { Adult ( } n=17471 \\
\text { child passengers) }\end{array}$ & p Value* \\
\hline \multicolumn{5}{|l|}{ Child passenger characteristics } \\
\hline Serious injury & $5.0(275)$ & $4.3(120)$ & 1.5 (2309) & \multirow{6}{*}{$\begin{array}{l}\leqslant 0.001 \\
\leqslant 0.001\end{array}$} \\
\hline Age group & & & & \\
\hline $0-3$ & $4.4(26)$ & $29.6(94)$ & $29.2(4124)$ & \\
\hline $4-8$ & $10.3(73)$ & $7.7(48)$ & $34.0(5798)$ & \\
\hline $9-12$ & 13.1 (158) & $20.9(93)$ & $23.4(4692)$ & \\
\hline $13-15$ & $72.2(822)$ & $41.8(265)$ & $13.4(2853)$ & \\
\hline \multicolumn{4}{|l|}{ Gender } & \multirow{3}{*}{0.02} \\
\hline Male & $40.5(429)$ & $41.6(216)$ & $38.9(8321)$ & \\
\hline Female & $59.5(655)$ & $58.4(288)$ & $51.1(9150)$ & \\
\hline \multirow{2}{*}{\multicolumn{4}{|c|}{$\begin{array}{l}\text { Front seating } \\
\text { Restraint status }\end{array}$}} & \multirow{5}{*}{$\begin{array}{l}\leqslant 0.001 \\
\leqslant 0.001\end{array}$} \\
\hline & & & & \\
\hline Appropriate & $72.3(725)$ & $68.7(326)$ & $65.0(10472)$ & \\
\hline Inappropriate & $19.3(181)$ & $28.3(115)$ & $32.3(6035)$ & \\
\hline Unrestrained & $8.4(166)$ & $3.0(49)$ & $2.7(879)$ & \\
\hline \multicolumn{5}{|l|}{ Driver characteristics } \\
\hline Mean (SE) age & $16.3(0.06)$ & $18.4(0.06)$ & $37.1(0.14)$ & \multirow{4}{*}{0.12} \\
\hline Gender & & & & \\
\hline Male & $36.5(482)$ & $31.8(185)$ & $28.5(4692)$ & \\
\hline Female & $63.5(602)$ & $68.3(319)$ & 71.5 (12779) & \\
\hline No restraint use & $4.3(83)$ & $7.4(45)$ & $3.4(920)$ & 0.22 \\
\hline \multicolumn{5}{|l|}{ Other occupant characteristics } \\
\hline Adult passenger presence & $17.0(117)$ & $10.3(59)$ & $27.9(4,476)$ & \multirow{4}{*}{$\begin{array}{l}\leq 0.001 \\
0.52\end{array}$} \\
\hline Number of passengers & & & & \\
\hline 1 & $39.9(365)$ & 44.3 (198) & $28.6(4,827)$ & \\
\hline$\geqslant 2$ & 60.1 (719) & $55.7(306)$ & $71.4(12,636)$ & \\
\hline \multicolumn{5}{|l|}{ Vehicle characteristics } \\
\hline Passenger car & $72.2(793)$ & $74.5(391)$ & 47.8 (9368) & \multirow[t]{5}{*}{$\leqslant 0.001$} \\
\hline Large van & $0.2(10)$ & $0.11(4)$ & $3.0(459)$ & \\
\hline Pickup truck & $5.4(62)$ & $4.2(27)$ & $6.2(977)$ & \\
\hline Sport utility vehicle & $13.2(105)$ & $17.2(60)$ & $18.5(2711)$ & \\
\hline Minivan & $9.1(114)$ & $3.9(22)$ & $24.5(3956)$ & \\
\hline \multicolumn{4}{|l|}{ Model year } & \multirow[t]{4}{*}{$\leqslant 0.001$} \\
\hline 1990-1993 & $32.1(365)$ & $35.0(167)$ & $20.5(4174)$ & \\
\hline 1994-1996 & $32.4(385)$ & 32.1 (173) & $28.3(5475)$ & \\
\hline 1997-2003 & $35.6(334)$ & $32.8(163)$ & $51.2(7817)$ & \\
\hline \multicolumn{4}{|l|}{ Crash severity } & \multirow[t]{4}{*}{$\leqslant 0.001$} \\
\hline No intrusion (drivable) & 36.7 (159) & $47.3(92)$ & $65.3(6752)$ & \\
\hline No intrusion (non-drivable) & $47.3(600)$ & $40.9(269)$ & 26.7 (7207) & \\
\hline Intrusion & $16.0(307)$ & $11.8(132)$ & $8.0(3384)$ & \\
\hline \multicolumn{5}{|c|}{$\begin{array}{l}\text { Note: There were no missing data for the following variables: serious injury, child's gender, driver's gender, } \\
\text { vehicle type, vehicle model year, adult passenger presence, and number of passengers; the weighted distribution of } \\
\text { missing data for the following variables was: } 0.02 \% \text { (unweighted } n=13 \text { ) for child's age, } 0.02 \% \text { (unweighted } \\
n=58 \text { ) for front row seating, } 0.3 \% \text { for restraint status (unweighted } n=111 \text { ), } 0.5 \% \text { for drivers' no restraint use } \\
\text { (unweighted } n=86 \text { ), } 0.6 \% \text { for crash severity (unweighted } n=157 \text { ). Because of missing data, only valid } \\
\text { percentages were reported. } \\
\text { * } p \text { Values were obtained from } \chi^{2} \text { tests. }\end{array}$} \\
\hline
\end{tabular}

with both teen groups experienced excess injury risk (for novice teens, OR $2.76,95 \%$ CI 2.10 to 3.63 ; for older teens, OR $2.83,95 \%$ CI 1.90 to 4.21 ). In model 3, after adjusting for crash severity, there is a $43 \%$ reduction in the odds ratio for children riding with novice teens (OR 1.58, 95\% CI 1.14 to 2.19 ) and a $24 \%$ reduction for those with older teens (OR $2.15,95 \%$ CI 1.42 to 3.26 ). In model 4 , after adjusting for vehicle type, child's front row seating and restraint status, there is a further $19 \%$ reduction in the odds ratio for children riding with novice teens (OR 1.37, 95\% CI 1.00 to 1.88 ) and a further 13\% reduction for those with older teens (OR 1.74, 95\% CI 1.14 to 2.66). As can be seen, the effect of the driver age groups on child injury risk varied considerably from the crude analysis to the final multivariate analyses by adding sequentially child age, and each set of modifiable factors. However, excess risks related to the driver's age still remained.

\section{DISCUSSION/CONCLUSION}

Previous research has documented the increased injury and death risks to teen drivers and their teen passengers. ${ }^{4} 53031$ While children riding with teen drivers may be more likely to be in a crash than children riding with other drivers, children in crashes with teen drivers should, in principle, fare no worse than children in crashes with mature drivers. However, our results extend those early findings to provide the first evidence of the excess risk to child passengers posed by teen drivers based on individual level crash data. Although only $4 \%$ of the children in our study were driven by teens, these children had about three times the injury risk when compared with those driven by adults.

In our study, about $40 \%$ of the children driven by teens were under 13 years, suggesting that teens not only drive other teens, but they also drive younger children. The age distribution of child passengers in our study differs from 
Table 2 Restraint status, front row seating, and serious injury by child age group among three driver groups (unweighted $\mathrm{n}=19$ 059); values are weighted \% (unweighted $\mathrm{n}$ )

\begin{tabular}{|c|c|c|c|c|c|c|c|c|}
\hline & $\begin{array}{l}\text { Appropriate } \\
\text { restraint }\end{array}$ & $\begin{array}{l}\text { Inappropriate } \\
\text { restraint }\end{array}$ & No restraint & p Value ${ }^{*}$ & Front row seating & p Value* & Serious injury & p Value ${ }^{*}$ \\
\hline Novice teens & & & & $<0.001$ & & $<0.001$ & & $<0.01$ \\
\hline $0-3$ & $75.2(21)$ & $24.5(4)$ & $0.4(1)$ & & 3.7 (1) & & $0(0)$ & \\
\hline $4-8$ & $0.2(1)$ & $97.5(65)$ & $2.4(6)$ & & $12.8(18)$ & & $2.4(15)$ & \\
\hline $9-12$ & 78.5 (117) & $16.1(26)$ & $5.3(15)$ & & $42.8(55)$ & & $4.5(36)$ & \\
\hline $13-15$ & $81.2(584)$ & $8.5(84)$ & $10.4(143)$ & & $67.4(499)$ & & 5.9 (224) & \\
\hline Older teens & & & & $<0.001$ & & $<0.001$ & & 0.42 \\
\hline $0-3$ & $72.3(64)$ & $27.6(29)$ & $0.1(1)$ & & $0.4(4)$ & & $2.9(20)$ & \\
\hline $4-8$ & $4.5(4)$ & $94.1(40)$ & $1.4(4)$ & & $25.3(16)$ & & $3.8(11)$ & \\
\hline $9-12$ & $63.9(71)$ & $34.0(15)$ & $2.1(7)$ & & $33.6(41)$ & & $4.0(22)$ & \\
\hline $13-15$ & 81.5 (187) & $12.6(30)$ & $6.0(37)$ & & $67.5(167)$ & & $5.7(67)$ & \\
\hline Adults & & & & $<0.001$ & & $<0.001$ & & $<0.001$ \\
\hline $0-3$ & 89.9 (3568) & $9.2(499)$ & $0.9(53)$ & & 3.8 (196) & & 1.0 (359) & \\
\hline $4-8$ & 23.6 (901) & $74.0(4607)$ & $2.4(270)$ & & 13.9 (1147) & & $1.6(772)$ & \\
\hline $9-12$ & $82.7(3695)$ & $13.5(661)$ & $3.8(300)$ & & 34.1 (1847) & & 1.7 (695) & \\
\hline $13-15$ & $84.4(2306)$ & $10.1(267)$ & $5.5(256)$ & & $56.2(1687)$ & & $1.9(481)$ & \\
\hline
\end{tabular}

Note: There were no missing data for serious injury; the weighted distribution of missing data for the following variables was: $0.02 \%$ (unweighted $n=13$ ) for child's age, $0.02 \%$ (unweighted $n=58$ ) for front row seating, $0.3 \%$ for restraint status (unweighted $n=111$ ). Because of missing data, only valid percentages were reported.

* $p$ Values were obtained from $\chi^{2}$ tests.

previous research ${ }^{32}$ in part due to our study inclusion criteria. Yet our data can provide a unique opportunity to examine how younger children fare with teen drivers. Our finding on the excess injury risk for children in teen crashes, particularly in novice teen crashes, was primarily explained by the more severe crashes those teen drivers incurred. These results are consistent with those of others, ${ }^{13}{ }^{14}$ which have demonstrated that teens are involved in more severe crashes than adult drivers. The crash severity is likely a function of the teen driver's inexperienced driving or risk taking behavior or immaturity. ${ }^{33}{ }^{34}$ The fact that crash severity reduces more excess risk in novice teen group than in older teen group may explain some effect of driving inexperience. Also, our data appear to support these findings of increased risky driving behavior among teens in that more children riding with teen drivers were in more severe crashes, and more children were riding with unrestrained teens, compared with those with adults.

Table 3 Sequential logistic regression models for the association between serious injury and teen drivers compared with adult drivers

\begin{tabular}{|c|c|}
\hline & $\begin{array}{l}\text { OR for child passengers' serious } \\
\text { injury }(95 \% \mathrm{Cl})\end{array}$ \\
\hline \multicolumn{2}{|c|}{ Model 1 (crude model) } \\
\hline Adults & 1.00 \\
\hline Older teens & 2.98 (2.02 to 4.41$)$ \\
\hline Novice teens & 3.46 (2.64 to 4.50 ) \\
\hline \multicolumn{2}{|c|}{ Model $2=$ model $1+$ child age group } \\
\hline Adults & 1.00 \\
\hline Older teens & $2.83(1.90$ to 4.21$)$ \\
\hline Novice teens & 2.76 (2.10 to 3.63$)$ \\
\hline \multicolumn{2}{|c|}{ Model $3=$ model $2+$ crash severity } \\
\hline Adults & 1.00 \\
\hline Older teens & $2.15(1.42$ to 3.26$)$ \\
\hline Novice teens & 1.58 (1.14 to 2.19$)$ \\
\hline \multicolumn{2}{|c|}{$\begin{array}{l}\text { Model } 4=\text { model } 3+\text { vehicle type }+ \\
\text { front row seating }+ \text { restraint status }\end{array}$} \\
\hline Adults & 1.00 \\
\hline Older teens & $1.74(1.14$ to 2.66$)$ \\
\hline Novice teens & 1.37 (1.00 to 1.88$)$ \\
\hline
\end{tabular}

Driver education and graduated driver licensing programs were designed to improve driving skills, and to help teen drivers avoid high risk driving situations. However, driver education failed to reduce the crash rates among teen drivers. ${ }^{35}$ Although several studies have demonstrated the effectiveness of graduated driver licensing laws on reducing both fatal and non-fatal crashes among teenage drivers, ${ }^{36-42}$ our data still demonstrate an excess injury risk to child passengers in teen crashes. Since parents are often more motivated to ensure the safety of their young children, interventions should ensure that parents are aware of the excess risk of allowing their teens to drive younger siblings. In addition, the promotion of ideal graduated driver licensing system in all American states ${ }^{35}$ and parental management of teen driving ${ }^{43}$ are needed to reduce the high crash rate among teen drivers and eventually decrease the excess injury risk for their child passengers.

The American Academy of Pediatrics and NHTSA recommend that all children under age 13 should be seated in the rear in an age appropriate restraint. Of note, our data demonstrated that novice teen drivers are more likely to transport child passengers under 13 in the front seat, not to restrain their child passengers, and to restrain children aged 4-8 inappropriately compared with adults. These behaviors, in part, contributed to the excess injury risk to children riding with teens. The provision of teenage passenger restriction in graduated driver licensing programs allows for exemptions if the passenger is a family member of the driver. Since there are often practical needs for such exemptions, our findings suggest that specific educational interventions regarding child passenger safety should be designed for teens. Provisions for age appropriate restraint and rear seating for child passengers should merit special consideration in graduated driver licensing programs.

More teens in our study drove older or smaller vehicles than adults. Driving or riding in older and smaller vehicles increased the injury risk for both drivers and passengers. ${ }^{11}{ }^{12}$ In addition, our results showed that vehicle type explained some of the increased injury risk associated with teen driver crashes. As recently suggested, more attention should be given to choosing a safe vehicle for teen drivers. ${ }^{44}$

Ten states included in our study (California, Delaware, Indiana, Nevada, New Jersey, New York, North Carolina, Illinois, Virginia, and West Virginia) initiated some form of 


\section{Key points}

- In 15 American states and the District of Columbia, between December 1998 and November 2002, compared with children in adult driver crashes, those in novice and older teen driver crashes experienced excess injury risk.

- A high rate of age inappropriate restraint for children aged 4-8 years occurs in both novice and older teen driver crashes.

- Front row seating for children $<13$ years were more common in novice teen driver crashes than in older teen or adult driver crashes.

- Much of the excess child injury risk found in both novice and older teen driver crashes is associated with crash severity, vehicle type, child passenger's restraint status, and child passenger's front row seating.

- Provisions for age appropriate restraint and rear seating for young child passengers should merit special consideration in graduate driver licensing programs.

passenger restrictions as part of their graduated driver licensing program during our study period. ${ }^{3}$ These restrictions would not be expected to have had an impact on young children riding with teen parents or siblings, as all states exempt transporting family members. However, due to the fact that 10 of our 15 participating states include the provision of passenger restriction or the need for adult supervision in their graduated driver licensing laws, we may underestimate the injury risk to young children driven by teens.

The results of this study may not be generalizable to occupants of uninsured vehicles, or vehicles older than model year 1990. Also, the use of single insurance company data may not be representative of the entire insured population. However, given the large market share of State Farm in the study regions, there is no reason to suspect that its population differs substantially from the overall insured population in these regions. This study relied on driver report for information on injuries, restraint use and seating position of children, and may be subject to information bias. However, between the driver and the crash investigator reports, agreement on seating position (front versus rear) was $99 \%$ for 170 children $(\kappa=0.99, p<0.0001)$, and agreement on restraint use was $89 \%$ for 164 children $(\kappa=0.74, p<0.0001)$. In addition, our results on child age specific restraint use and seating position are similar to those of other recently reported population based studies. ${ }^{45} 46$

While improvements in age appropriate restraint use and rear seating for young children continue to be made in the United States, ${ }^{46}{ }^{47}$ these findings suggest ways in which graduated driver licensing laws may be further enhanced to better protect child passengers from the excess injury risk associated with teen crashes.

\section{ACKNOWLEDGEMENTS}

The authors would like to thank State Farm for their financial support of this work through the Partners for Child Passenger Safety project, many dedicated claim representatives and personnel from State Farm, and the parents who generously agreed to participate in the study.

\section{Authors' affiliations}

I G Chen, F K Winston, Department of Pediatrics, Children's Hospital of Philadelphia, Philadelphia, USA
M R Elliott, Center for Clinical Epidemiology and Biostatistics, University of Pennsylvania School of Medicine, USA

D R Durbin, Department of Pediatrics, Children's Hospital of

Philadelphia, Philadelphia and Center for Clinical Epidemiology and

Biostatistics, University of Pennsylvania School of Medicine, USA

\section{REFERENCES}

1 National Highway Traffic Safety Administration. Fatality reporting system, 2002/2003. Washington, DC: US Department of Transportation. Available at: http://www-nrd.nhtsa.dot.gov/pdf/nrd-30/NCSA/Rpts/2003/ Assess02.pdf (accessed 28 July 2003).

2 National Highway Traffic Safety Administration. Younger driver. Traffic safety facts 2001. DOT HS 809 483. Washington DC: Department of Transportation, 2001.

3 Insurance Institute for Highway Safety. Graduated licensing: a blueprint for North America. 2004. Arlington, VA: Insurance Institute for Highway Safety. Available at: http://www.hwysafety.org/safety\%5Ffacts/teens/blueprint.pdf (accessed 8 January 2004).

4 Preusser DF, Ferguson SA, Williams AF. The effect of teenage passengers on the fatal crash risk of teenage drivers. Accid Anal Prev 1998;30:217-22.

5 Chen LH, Baker SP, Braver ER, et al. Carrying passengers as a risk factor for crashes fatal to 16- and 17-year-old drivers. JAMA 2000;283:1578-82.

6 Chen LH, Braver ER, Baker SP, et al. Potential benefits of restrictions on the transport of teenage passengers by 16 and 17 year old drivers. Inj Prev 2001;7:129-34.

7 Winston FK, Durbin DR, Kallan MJ, et al. The danger of premature graduation to seat belts for young children. Pediatrics 2000;105:1179-83.

8 Durbin DR, Chen I, Elliott $M$, et al. Factors associated with front row seating of children in motor vehicle crashes. Epidemiology 2004;15:345-9.

9 Durbin DR, Elliott MR, Winston FK. Belt-positioning booster seats and reduction in risk of injury among children in vehicle crashes. JAMA 2003;289:2835-40.

10 Durbin DR, Elliott $M$, Arbogast KB, et al. The effect of seating position on risk of injury for children in side impact collisions. Annual Proceedings of the Association for the Advancement of Automotive Medicine 2001:61-72.

11 Cammisa MX, Williams AF, Leaf WA. Vehicles driven by teenagers in four states. J Safety Res 1999;30:25-30.

12 Williams AF, Preusser DF, Lund AK, et al. Cars owned and driven by teenagers. Transportation Quarterly 1987:41:177-88.

13 McGwin G Jr, Brown DB. Characteristics of traffic crashes among young, middle-aged, and older drivers. Accid Anal Prev 1999;31:181-98.

14 Ryan GA, Legge M, Rosman D. Age related changes in drivers' crash risk and crash type. Accid Anal Prev 1998;30:379-87.

15 National Highway Traffic Safety Administration. Traffic safety facts 2001. DOT HS 809 484. Washington, DC: Department of Transportation, 2001:103 (table 68).

16 Kim S, Kim K. Personal, temporal and spatial characteristics of seriously injured crash-involved seat belt non-users in Hawaii. Accid Anal Prev 2003;35:121-30.

17 National Highway Traffic Safety Administration. Fatality analysis reporting system, 1995-2001. Washington, DC: NHTSA, 2002.

18 Durbin DR, Bhatia E, Holmes JH, et al. Partners for child passenger safety: a unique child-specific crash surveillance system. Accid Anal Prev 2001;33:407-12.

19 Association for the Advancement of Automotive Medicine. The abbreviated injury scale, 1990 revision. Barrington, IL: AAAM, 1990.

20 Durbin DR, Winston FK. Development and validation of the injury severity assessment survey/parent report. Arch Pediatr Adolesc Med 1999; 153:404-8

21 American Academy of Pediatrics. Selecting and using the most appropriate car safety seats for growing children: guidelines for counseling parents. Pediatrics 2002;109:550-3.

22 American Academy of Pediatrics. Selecting and using the most appropriate car safety seats for growing children: guidelines for counseling parents (RE9618). ELK Grove Village, IL: American Academy of Pediatrics, 2003. Available at: http://www.aap.org/family/01352.htm (accessed 1 January 2003).

23 National Highway Traffic Safety Administration. The use of child restraints in 2002. Available at: http://www.nhtsa.dot.gov/people/injury/childps/ index.cmf (accessed 1 May 2003).

24 National Highway Traffic Safety Administration. Child passenger safety, Available at: http://www.nhtsa.dot.gov/people/injury/airbags/ Airbags.html (accessed 5 August 2004).

25 Insurance Institute for Highway Safety/Highway Loss Data Institute. VINDICATOR 2003, version 2. Arlington, VA: 2003.

26 Korn EL, Graubard BI. Examples of differing weighted and unweighted estimates from a sample survey. The American Statistician 1995:49:291-5.

27 Research Triangle Institute. SUDAAN, software for the statistical analysis of correlated data. Research Triangle Park, NC: Research Triangle Institute, 2001.

28 Zhang J, Yu KF. What's the relative risk? A method of correcting the odds ratio in cohort studies of common outcomes. JAMA 1998;280:1690-1.

29 Robertson LS. Injury epidemiology. New York: Oxford University Press, 1998.

30 Karp RS, Williams AF. Teenage drivers and motor vehicle deaths. Accid Anal Prev 1984;15:15-63.

31 Insurance Institute for Highway Safety. Youngest drivers at risk. Status report. Arlington, VA: IIHS, 1998;33:1-2.

32 Miller TR, Spicer RS, Lestina DC. Who is driving when unrestrained children and teenagers are hurt? Accid Anal Prev 1998;30:839-49. 
33 Jonah BA, Dawson NE. Youth and risk: age differences in risky driving, risk perception, and risk utility. Alcohol Drugs Driving 1987;3:13-29.

34 Everett SA, Shults RA, Barrios LC, et al. Trends and subgroup differences in transportation-related injury risk and safety behaviors among high school students, 1991-1997. J Adolesc Health 2001 28:228-34.

35 Mayhew DR, Simpson HM. The safety value of driver education and training Inj Prev 2002;8:ii3-7; discussion ii7-8 (suppl 2).

36 Foss RD, Feaganes JR, Rodgman EA. Initial effects of graduated driver licensing on 16-year-old driver crashes in North Carolina. JAMA 2001;286:1588-92

37 Shope JT, Molnar U, Elliott MR, et al. Graduated driver licensing in Michigan early impact on motor vehicle crashes among 16-year-old drivers. JAMA 2001;286:1593-8.

38 Shope JT, Molnar U. Graduated driver licensing in the United States: evaluation results from the early programs. J Safety Res 2003;34:63-9.

39 McKnight AJ, Peck RC. Graduated driver licensing and safer driving. I Safety Res 2003;34:85-9.
40 Preusser DF, Leaf WA. Provisional license. J Safety Res 2003;34:45-49. 41 Elliott MR, Shope JT. Use of a bayesian changepoint model to estimate effects of a graduated driver's licensing program. J Data Sci 2003;1:43-63.

42 Ulmer RG, Preusser DF, Williams AF, et al. Effect of Florida's graduated licensing program on crash rate of teenage drivers. Accid Anal Prev 2000;32:527-32.

43 Simons-Morton BG, Hartos JL, Leaf WA. Promoting parental management of teen driving. Inj Prev 2002;8:ii24-30; discussion ii30-1 (suppl 2).

44 Ferguson SA. Other high-risk factors for young drivers - how graduated licensing does, doesn't or could address them. J Safety Res 2003:34:71-7.

45 Glassbrenner D. The use of child restraints in 2002. Washington, DC: National Highway Traffic Safety Administration, 2003.

46 Kindelberger J, Starnes M. Moving children from the front seat to the back seat: the influence of child safety campaigns. Washington, DC: National Highway Traffic Safety Administration, 2003.

47 Winston FK, Chen IG, Elliott MR, et al. Recent trends in child restraint practices in the United States. Pediatrics 2004; 113:e458-64.

\section{COCHRANE CORNER}

\section{Cochrane Injuries Group}

ontributors to Injury Prevention frequently lament the inadequacy of the evidence base on interventions intended to prevent injury. The most recent reviews completed by the Cochrane Injuries Group (CIG) highlight the fact that some types of injury are better served by the evidence base, such as it is, than are others.

Injuries from falls are recognised as a major threat to elderly people. There are several measures that are known to be efficacious in reducing the risk of falling for old people individually, but how effective are prevention programmes conducted at community level in reducing the incidence of fall related injury? One of CIG's latest systematic reviews has addressed this question- "Population-based interventions to prevent fall-related injury in older people". ${ }^{1}$ The reviewers found only five quality trials that met their inclusion criteria. However, in all five the rate of injuries caused by falls decreased after population based programmes had been introduced. Reductions achieved ranged from 6\% to 33\%. Although they call for more research to be done, the reviewers conclude that population based falls prevention programmes are effective in reducing injuries sustained by people aged over 65 .

Here then is a sector of the evidence base on injury prevention where good evidence is starting to accumulate. Things are not, however, looking so good elsewhere.

We have recently published two CIG reviews on the treatment of organophosphorus poisoning. ${ }^{23}$ This is one of the most common types of poisoning worldwide, most of the victims being in developing countries. Self poisoning is responsible for many of the cases. Oximes-drugs which appear to reactivate the enzyme acetylcholinesterase, which organophosphorus inhibits-form part of the standard treatment. However, a systematic review of evidence for the use of oximes found that very few studies have taken place to evaluate this treatment, ${ }^{2}$ and these had been inconclusive. A further treatment option involves alkalanisation, ${ }^{3}$ with sodium bicarbonate used in most cases. Although there are theoretical grounds for thinking that this could be useful, virtually no research has been done and the effectiveness of this approach must remain in the realm of speculation. Thus we have yet another situation where the lack of effective treatment for a condition ${ }^{4}$ has highlighted the need to know which prevention measures are effective.

In what kind of state then is the evidence base on poisoning prevention? One of the admirable features of the Cochrane Library is that, as well as including all Cochrane's systematic reviews, it allows users to see what systematic reviews have been produced by others. A search of the Library's Database of Abstracts of Reviews of Effectiveness (DARE) is undoubtedly the best way of tracking down non-Cochrane systematic reviews. A DARE search, however, reveals no reviews at all that specifically address interventions to prevent any kind of poisoning.

There is one poisoning prevention review in CIG's pipeline. Reviewers working with us are examining the effectiveness of childproof containers. We have thus made a very modest start in this neglected area. More, much more, remains to be done and we would very much like to hear from anyone who would like to take on a systematic review of the evidence for the effectiveness of an intervention to prevent poisoning.

Cochrane Iniuries Group; paulchinnock Chinnock

\section{REFERENCES}

1 McClure R, Turner C, Peel N, et al. Population-based interventions to prevent fall-related injury in older people. The Cochrane database of systematic reviews 2005 (in press).

2 Buckley NA, Eddleston M, Szinicz L. Oximes for acute organophosphate pesticide poisoning. The Cochrane database of systematic reviews 2005 (in press).

3 Roberts D, Buckley NA. Alkalinisation for organophosphorus pesticide poisoning. The Cochrane database of systematic reviews 2005 (in press).

4 Buckley NA, Roberts D, Eddleston M. Overcoming apathy in research on organophosphate poisoning. BMJ 2004; 329:1231-3. 